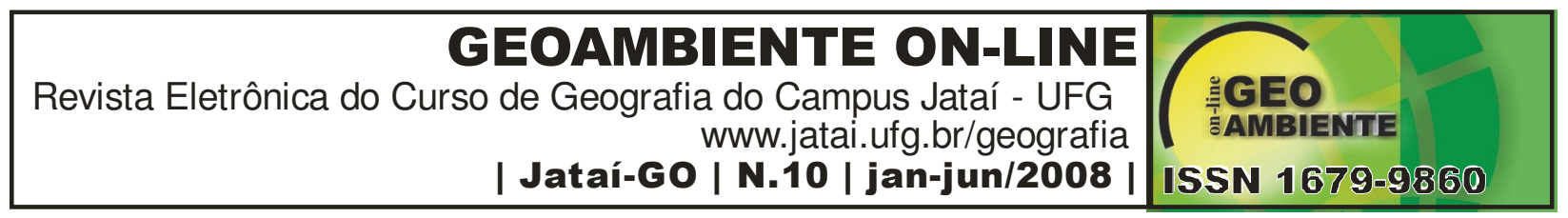

\title{
SEGREGAÇÃO E PERIFERIZAÇÃO URBANA EM CIDADES PEQUENAS: O CASO DE GAVIÃO PEIXOTO - SP•
}

\author{
Leandro Marcos Tessari ${ }^{1}$, Roberto Braga ${ }^{2}$
}

( 1- Mestrando em Geografia pela Universidade Estadual Paulista (UNESP/IGCE) Rio Claro - SP. Endereço: Av. República do Líbano, 1375, Jd. Cruzeiro do Sul, São Carlos/SP, CEP: 13572-081, e-mail: lmtessari@yahoo.com.br, 2 - Professor Doutor do Departamento Territorial e Geoprocessamento da UNESP/IGCE - Rio Claro, e-mail: rbraga@ rc.unesp.br.)

\section{Resumo}

Este artigo busca compreender os elementos geradores do processo de segregação e de periferização urbana no município de Gavião Peixoto - SP. Para a execução do trabalho utilizou-se: levantamento bibliográfico e levantamento de campo (questionários, levantamento cartográfico), dados estatísticos em fontes oficiais como a Fundação SEADE e da prefeitura da citada cidade. A periferia urbana de Gavião Peixoto encontra-se segregada do restante da cidade. Este isolamento é resultado da ação do poder público Estadual que na década de 1990, instalou um Conjunto Habitacional Popular - COHAB - na franja urbana-rural da cidade.

Palavras-chaves: Segregação. Periferização. Cidades Pequenas. Gavião Peixoto.

\section{Abstract \\ SEGREGATION AND PERI-URBAN CONSTRUCTION IN A SMALL TOWN: THE CASE OF GAVIÃO PEIXOTO (SP)}

This article searches to understand the generating elements of the segregation process and peri-urban construction in the city of Gavião Peixoto (SP). For execution of this work it was used: bibliographical and field survey (questionnaires, cartographic survey), statistics data from official sources, such as SEADE Foundation, and local data of the City. The Gavião Peixoto urban periphery is isolated of the city. This isolation is a result from the action of the State public power that, in the 90's, installed a Popular Habitacional Set - COHAB - in the urban-agricultural fringe of the city.

Word-keys: Segregation. Small Town. Gavião Peixoto.

\footnotetext{
- Recebido para publicação em 02 de Março de 2008; Aprovado para publicação em 13 de Junho de 2008
} 


\section{GEOAMBIENTE ON-LINE \\ Revista Eletrônica do Curso de Geografia do Campus Jataí - UFG \\ www.jatai.ufg.br/geografia \\ | Jataí-GO | N.10 | jan-jun/2008 |

\section{1 - Introdução}

O intenso processo de urbanização verificado nas últimas décadas tem resultado na formação de áreas periféricas associadas, na maioria das vezes, ao processo de segregação socioespacial. Tais fatos têm contribuído tanto para a fragmentação do tecido urbano como influenciando nas condições de vida da população. Alguns elementos podem ser destacados: o próprio sistema produtivo, no qual não permite uma equânime distribuição de renda; a falta de uma política de desenvolvimento e expansão urbana, voltada para uma melhor ocupação e uso do solo; a atuação dos agentes de produção do espaço urbano (setor público e privado), no qual, através da implantação de loteamentos e obras públicas, acabam por promover a segregação socioespacial nos centros urbanos; atuação da especulação imobiliária que permite o acesso à mercadoria "terra" de maneira diferenciada, ou seja, somente para aqueles que têm condições reais de pagamento.

Alguns destes elementos contribuem para uma inadequada ocupação e uso do solo, influenciando também no bem-estar social da população. Nesse sentido, o papel do planejamento se apresenta como uma ferramenta que auxilia em uma estruturação urbana adequada, para os diversos segmentos da sociedade.

Neste trabalho busca-se compreender o processo de periferização/segregação urbana no município de Gavião Peixoto, no Estado de São Paulo, analisando a origem e atuação dessa periferia em um município de pequeno porte, recentemente emancipado. Informações estatísticas e resultados de pesquisas de campo contribuem para entender o que está se processando no espaço urbano em estudo. No que diz respeito a essa reflexão, é importante salientar as perspectivas de desenvolvimento do município com a instalação do Pólo Aeroespacial e os possíveis reflexos desse empreendimento no processo de urbanização, em especial, da periferização.

A escolha da área de estudo surgiu a partir da propaganda da instalação do Pólo Aeroespacial, haja vista que antes da chegada desse empreendimento em Gavião Peixoto, o município possuía pouca expressividade no contexto regional, como também no cenário estadual e nacional.

\section{2 - A Periferia}

As periferias urbanas vêm passando por inúmeras transformações no que diz respeito a sua forma de ocupação. No que se refere à localização, a escala da periferia é muito mais 


\section{GEOAMBIENTE ON-LINE \\ Revista Eletrônica do Curso de Geografia do Campus Jataí - UFG \\ www.jatai.ufg.br/geografia \\ | Jataí-GO | N.10 | jan-jun/2008 |

ampla, pois "nela cabe tudo": centros urbanos densos e comércio ativo, muitos parcelamentos de lotes de diversos níveis e com padrões urbanísticos e habitacionais variados. À medida em que a periferia vai sendo integrada urbanisticamente, nova periferia vai surgindo em outros pontos, tão livre e tão desorganizada como era primitivamente (LOWEN, 1990).

A ausência de intervenções públicas nos espaços periféricos representam todo um mecanismo da produção estrutural, ligado à uma dinâmica do atual modelo econômico. Carlos (1994), destaca que o termo periferia possui um duplo sentido, sendo

o primeiro, com áreas nas bordas da mancha urbana, que podem ser caracterizadas como de expansão da cidade e que engloba tanto uma população de alta renda quanto de baixa renda; o segundo, que se refere à idéia de periferia como uma manifestação espacial particular da problemática da reprodução da força de trabalho em um contexto urbano,tendo em vista que a cidade se mostra como um campo privilegiado das lutas de classe. (CARLOS, 1994, p.168).

A cidade, responsável pela dinamização das relações sociais, bem como pelas desigualdades oriundas dessa mesma relação, representa, de maneira mais contundente, todo um fenômeno resultante do processo de reprodução da lógica capitalista de produzir. A urbanização da sociedade não compreende, portanto, apenas a dinâmica demográfica de concentração do homem ou a dinâmica econômica de concentração de riqueza, nem as formas concretas que expressam ou determinam essas dinâmicas, mas seu conteúdo social e cultural (SPÓSITO, 2001).

Por outro lado, os investimentos em infra-estrutura nas áreas periféricas (basicamente água encanada, luz elétrica, pavimentação asfáltica, sistema de drenagem, etc.) podem levar cinco, dez, quinze anos, dependendo da posição do bairro na estrutura urbana. Sendo assim, a periferização representa, não somente uma porção do espaço localizado na porção urbanorural da cidade, mas também "localizada" na periferia das políticas públicas. Ainda, com relação aos investimentos do Estado nas porções periféricas das cidades, não suplanta uma questão de cunho mais aprofundado, ou seja, uma reversão do processo de segregação socioespacial. O processo de periferização pressupõe, anteriormente, toda uma fragmentação do espaço urbano em conjunto com o fenômeno da segregação socioespacial.

Conforme Ribeiro e Lago (1994),

a periferia deixa de ser um espaço aberto, e neste sentido uma fronteira, cuja lógica de crescimento permitiu a difusão da propriedade da terra urbana. Por outro lado, tal tendência convive com outra dilateralmente oposta, isto é, a produção de espaços 


\section{GEOAMBIENTE ON-LINE \\ Revista Eletrônica do Curso de Geografia do Campus Jataí - UFG \\ www.jatai.ufg.br/geografia \\ | Jataí-GO | N.10 | jan-jun/2008

residenciais privilegiados, destinados às camadas de alto poder aquisitivo, separados territorialmente do resto da cidade. (RIBEIRO; LAGO, 1994, p.11).

Vale, contudo, ressaltar que a discussão da periferia inicia-se claramente como base de um processo de produção do espaço urbano. O termo periferia não é imposto a seus moradores; ele é sempre utilizado e claramente percebido por seus produtores como uma apropriação desigual do espaço urbano. A periferização representa, a priori, um resultado do processo de expansão do tecido urbano, incorporando à cidade porções de glebas que antes tinham o uso rural. No entanto, os espaços periféricos atuais dos centros de grande e médio porte têm se diferenciado da noção clássica da periferia, sendo pautada no preceito da segregação da pobreza e da insalubridade em conjunto com a deficiência em infra-estrutura urbana. Percebe-se assim, o surgimento, nessas áreas, de novas modalidades de segregação sócio-espacial através da construção de espaços privilegiados e excludentes devido aos altos preços cobrados pelo acesso.

\section{1 - As Formas de Ocupação da Periferia}

Para Marques e Bichir (2001), as áreas periféricas,

representam um território sem Estado, quase totalmente intocadas pelas políticas públicas, exceto pelos empreendimentos habitacionais massificados implementados a partir da década de 1960, o que teria levado à constituição de espaços com condições de vida bastante precárias [...] Nesse sentido, o território das áreas periféricas representam a espoliação e seriam construídas e reconstruídas pelo Estado e pela própria dinâmica da acumulação capitalista. (MARQUES; BICHIR, 2001, p. 10-11).

Deve-se ressaltar outros aspectos referentes à propriedade da terra, pois têm-se na periferia todas as formas consagradas de propriedade, e mais algumas outras semi-oficiais e não-oficiais. Com relação ao "sistema urbano", a periferia, mantém uma situação de relativo isolamento e, geralmente, de especialização do uso do solo para formas de moradia que atendem diferentes estratos socioeconômicos, ou seja, de alta e de baixa renda. A expansão urbana para as áreas ditas periféricas, gera tanto uma segregação da pobreza quanto da riqueza. Entretanto, na articulação urbano-periférica da cidade, tem-se distintos modelos que na grande maioria das vezes encontram-se próximos, favorecendo ou não a auto-segregação, 


\section{GEOAMBIENTE ON-LINE \\ Revista Eletrônica do Curso de Geografia do Campus Jataí - UFG \\ www.jatai.ufg.br/geografia \\ | Jataí-GO | N.10 | jan-jun/2008

como os conjuntos habitacionais populares, os condomínios fechados horizontais, os loteamentos clandestinos etc.

Assim, quando se procura analisar e entender a dinâmica urbana presente em cidades pequenas e interioranas, em especial no Estado de São Paulo, tem-se a imagem de um espaço que se desenvolve gradativamente, primado pela organização, por ações e estratégias de planejamento urbano que atendam tanto a qualidade de vida dos habitantes locais quanto a qualidade e quantidade dos serviços prestados. No entanto, tal imagem só ocorre, infelizmente, no ideário humano, já que o processo de periferização/segregação urbana presente em Gavião Peixoto, guardada as devidas proporções ao porte da cidade, se materializa na forma e processo, como um campo de interesse diverso, que antes ocorriam somente em áreas metropolitanas e em cidades de maior porte. Acrescenta-se também, a existência de outros fenômenos que nas últimas décadas passaram a ser observados também em cidades médias e pequenas, dentre eles: os conjuntos habitacionais construídos pelo Estado. Grande parte da população trabalhadora brasileira, por possuir baixo rendimento, fica excluída de participar do processo de aquisição da casa própria, fornecida pelo poder público; e os condomínios fechados de alto padrão, que favorecem uma auto-segregação; os loteamentos clandestinos e por fim, a favela.

Mautner (1999) ao analisar os loteamentos clandestinos como uma outra forma de ocupação da periferia, destaca que

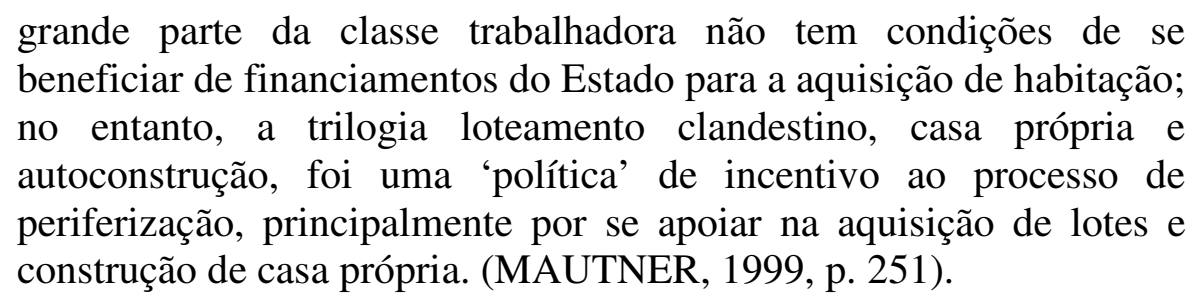

Complementa-se ainda que as favelas, forma mais precária de periferia, não seguem nenhum padrão urbanístico. Seu sistema viário é estreito e tortuoso composto exclusivamente por becos e vielas, inexistência de ordenação dos lotes, enfim carência absoluta de infra-estrutura e equipamentos urbanos.

Por fim, o papel do Estado enquanto instância reguladora "é percebido com uma instituição que paira acima das relações sociais, pois alguns de seus benefícios são apropriados, várias de suas regras ou normas são burladas ou transgredidas, mas a referência é mantida.” (MAUTNER, 1999, p. 252-253). Assim, nota-se as políticas que, a priori, 


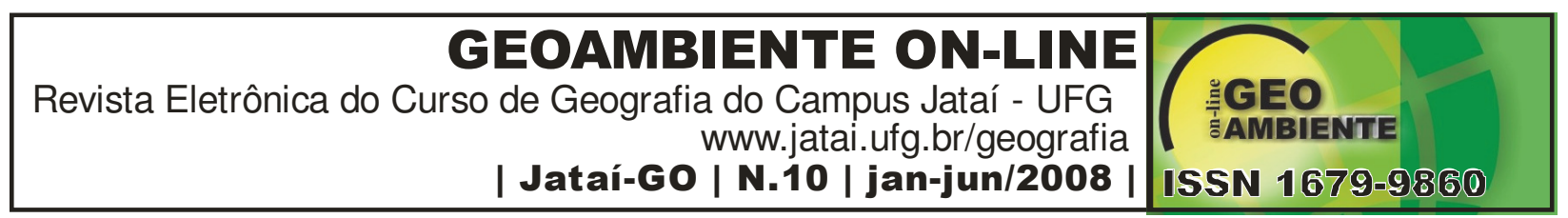

deveriam solucionar uma problemática inicial, acabam por provocar um agravamento das mais diversas situações presentes no espaço urbano: o fenômeno da periferização/segregação.

\section{3 - Caracterização da Área de Estudo}

\section{1 - Enfoque Regional}

O município de Gavião Peixoto - SP, localiza-se a trezentos quilômetros a noroeste da capital e, integra-se na Região Administrativa Central do Estado de São Paulo a quarenta quilômetros de Araraquara, conforme destaca a figura 01 .

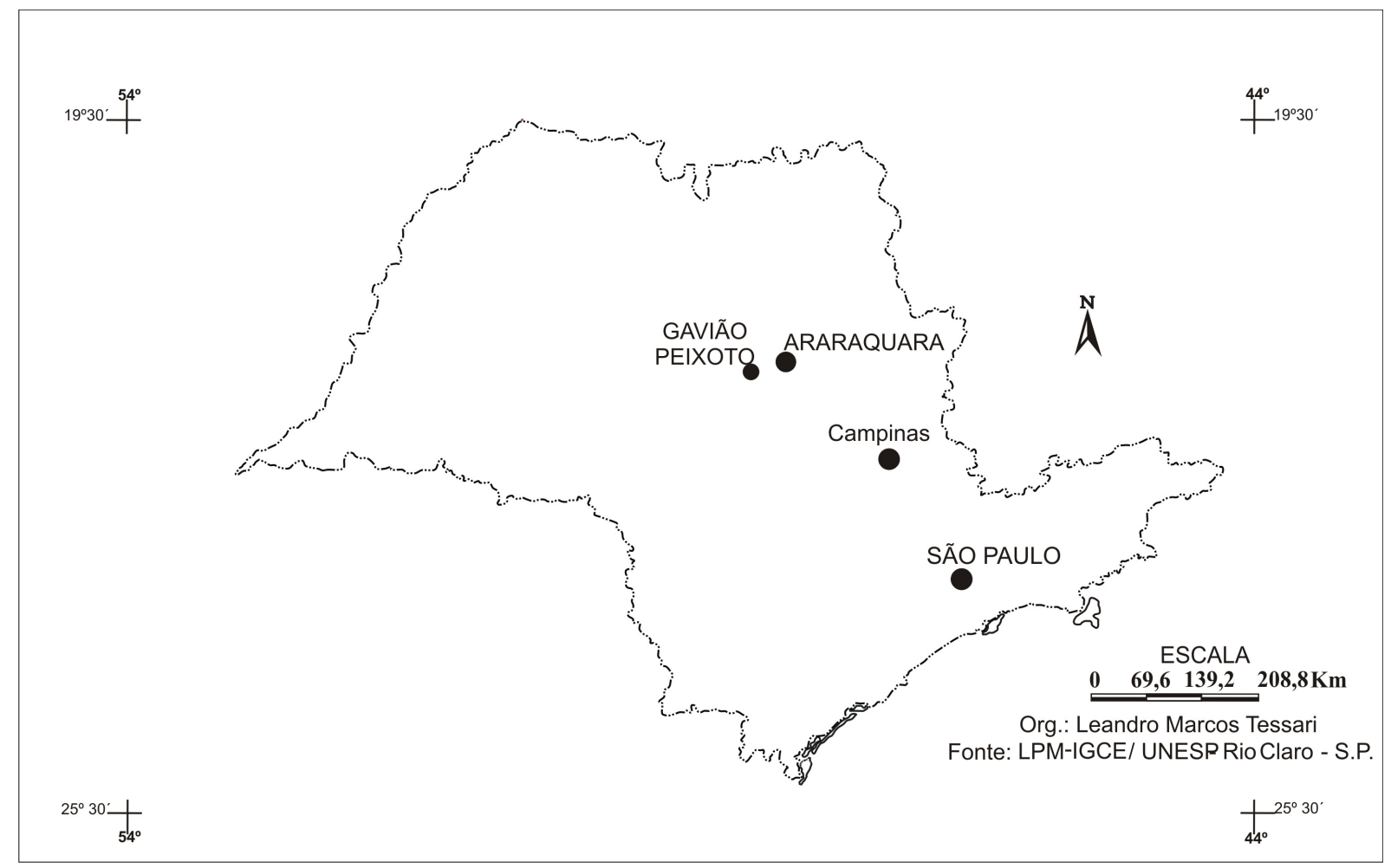

Figura 1: Localização do município de Gavião Peixoto no Estado de São Paulo.

Neste município predominam as culturas tecnificadas de cana-de-açúcar e laranja, ligadas exclusivamente a agroindústria. Toda essa produção agrícola é destinada ao município vizinho de Araraquara. Sendo assim, no que toca a centralidade mínima de uma cidade local, expressa no modelo clássico de hierarquia urbana, Gavião Peixoto não é responsável diretamente pela centralidade de seu campo. Ressalta-se que, mesmo com a chegada do Pólo Aeroespacial, a mão-de-obra recém-contratada ${ }^{1}$ e extremamente especializada não reside na sua área urbana.

\footnotetext{
${ }^{1}$ A mão-de-obra empregada no Pólo Aeroespacial reside nas cidades de Araraquara e São Carlos.
} 


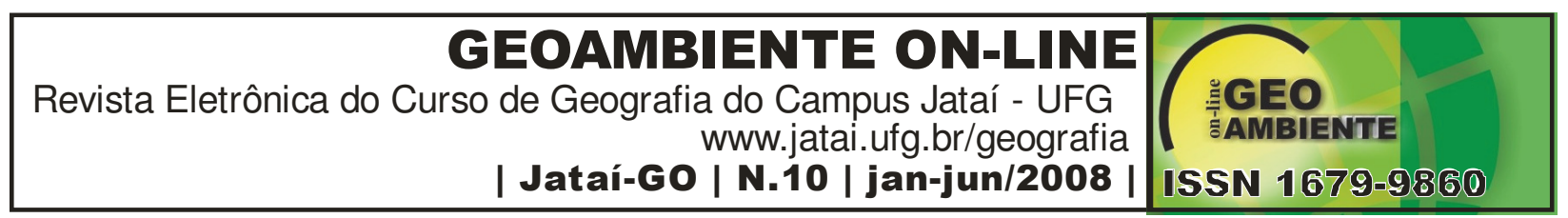

A cidade de Araraquara desempenha um papel primordial no cenário regional, devido a sua diversificada gama de serviços oferecidos que compreende todos os setores da economia. Essa cidade tem-se firmado, constantemente, como um centro regional voltado, em especial, para o comércio, garantindo assim, o atendimento de sua população, bem como a população dos municípios vizinhos. Uma outra cidade da região, São Carlos, está recebendo inúmeros investimentos a partir da chegada do Pólo Aeroespacial em Gavião Peixoto, sendo considerada um Pólo Tecnológico devido aos inúmeros centros de pesquisa já instalados.

\section{2 - O Enfoque Local}

Distrito de Araraquara, Gavião Peixoto tornou-se município a partir de maio de 1995. A área total do município é de 246 quilômetros quadrados, porém, com uma área urbana atual reduzida (figura 02). O restante da área que compreende o município fica destinado ao cultivo de cana-de-açúcar e de laranja e, com menor expressão territorial, o plantio de café e milho, além de, recentemente, abrigar o Pólo Aeroespacial. No Pólo Aeroespacial, a Empresa Brasileira de Aeronáutica S.A. - EMBRAER -, principal empresa já instalada, está construindo um complexo aeroespacial que inclui uma fábrica, um centro de treinamento para pilotagem, manutenção de aeronaves e uma pista de testes. 

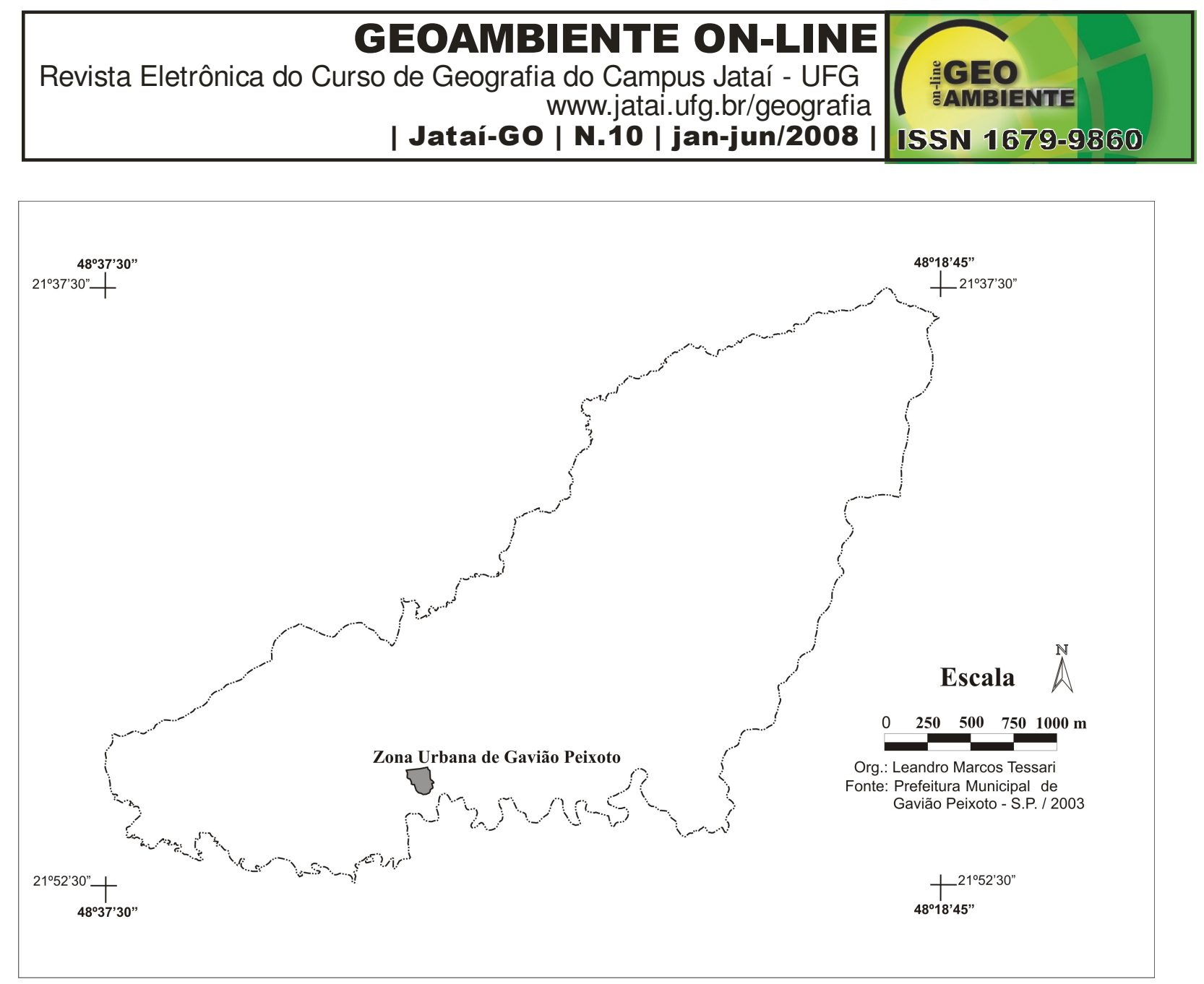

Figura 2: Área do Município de Gavião Peixoto - SP.

De acordo com os dados da Fundação Sistema Estadual de Análise de Dados (SEADE), no ano de 2000, o município ${ }^{2}$ possuía uma população total de 4.123 habitantes, dos quais cerca de 66,6\% encontram-se instalados na sua área urbana. Conforme dados apresentados pelo Instituto de Pesquisas Tecnológicas, no projeto do plano diretor para Gavião Peixoto (2003), a composição da população por faixa etária mostra que $43 \%$ possuem idade inferior a 19 anos, $18 \%$, entre 20 e 29 anos, 24\%, entre 30 e 49 anos, $10 \%$, entre 50 e 64 anos, e 5\% com idade superior a 65 anos, o que indica uma maior predominância de jovens no município. A partir destes dados convém salientar que, em breve, essa população jovem passará a ser considerada economicamente ativa e haverá a necessidade de ampliação do número de postos de trabalho.

Segundo os dados produzidos pela Fundação SEADE, nota-se que o crescimento da população tem se mantido constante, conforme indica a tabela 01 .

${ }^{2}$ A caracterização socioeconômica do município de Gavião Peixoto teve como base os dados da Fundação SEADE (Sistema Estadual de Análise de Dados), pesquisas de campo, além de informações fornecidas pela Prefeitura. 


\section{GEOAMBIENTE ON-LINE \\ Revista Eletrônica do Curso de Geografia do Campus Jataí - UFG \\ www.jatai.ufg.br/geografia \\ | Jataí-GO | N.10 | jan-jun/2008

Tabela 01 - Evolução Populacional de Gavião Peixoto (1997-2007)

\begin{tabular}{c|c|c|c|c}
\hline Anos & $\begin{array}{c}\text { População } \\
\text { Rural }\end{array}$ & $\begin{array}{c}\text { População } \\
\text { Urbana }\end{array}$ & $\begin{array}{c}\text { População } \\
\text { Total }\end{array}$ & $\begin{array}{c}\text { Taxa de } \\
\text { Urbanização } \\
(\%)\end{array}$ \\
\hline 1997 & 1.596 & 2.427 & 4.023 & 60,33 \\
\hline 1998 & 1.524 & 2.533 & 4.057 & 62,44 \\
\hline 1999 & 1.452 & 2.640 & 4.092 & 64,52 \\
\hline 2000 & 1.376 & 2.747 & 4.123 & 66,63 \\
\hline 2005 & 1.252 & 3.146 & 4.398 & 71,53 \\
\hline 2007 & 1.219 & 3.288 & 4.507 & 72,95 \\
\hline
\end{tabular}

Fonte: Fundação SEADE, 2007.

Observa-se que o município registrou crescimento de sua população total e urbana no período analisado, e decréscimo da população rural. O crescimento da população urbana ocorreu de maneira praticamente constante, sendo um pouco mais significativo entre 2000 a 2005. A Taxa de Urbanização encontra-se em constante crescimento, porém, encontra-se abaixo da estimativa do Estado de São Paulo que é de 93,75\%, um diferencial de 20,80\%.

Vale salientar ainda que a taxa de crescimento anual da população do município de Gavião Peixoto, no período de 2000 a 2007, é de 1,28\%, valor de crescimento inferior quando comparado aos dados da Região Administrativa Central $^{3}$ e ao do estado de São Paulo, ou seja, $1,53 \%$ e $1,50 \%$, respectivamente. Cabe aqui uma ressalva para confirmar que as cidades médias do interior paulista têm apresentado, nas últimas décadas, um crescimento percentual significativo de população. Faz-se necessário entender mais profundamente quais os elementos fomentadores desse processo e quais desdobramentos poderão se materializar nesses espaços urbanos, com toda a certeza temas novos de pesquisas se abrem nessa direção.

A dinâmica econômica do município tem como base a participação dos diferentes setores. Notadamente é o setor primário que se destaca em Gavião Peixoto, correspondendo a um total de $91 \%$ da receita do município. Com relação aos demais setores da economia convêm destacar que o setor secundário não possuía participação, no município, até a instalação do Pólo Aeroespacial, em especial das empresas Embraer e Kawasaki. O setor terciário da economia local, em especial o comércio, possui pouca expressividade. Em Gavião Peixoto, nota-se um predomínio exclusivo do chamado circuito inferior da economia, que

\footnotetext{
${ }^{3}$ A Região Administrativa Central do Estado de São Paulo é composta pelos seguintes municípios: Américo Brasiliense, Araraquara, Boa Esperança do Sul, Borborema, Cândido Rodrigues, Descalvado, Dobrada, Dourado, Fernando Prestes, Gavião Peixoto, Ibaté, Ibitinga, Itápolis, Matão, Motuca, Nova Europa, Porto Ferreira, Ribeirão Bonito, Rincão, São Carlos, Santa Ernestina, Santa Lucia, Santa Rita do Passa Quatro, Tabatinga, Taquaritinga e Trabiju.
} 


\section{GEOAMBIENTE ON-LINE \\ Revista Eletrônica do Curso de Geografia do Campus Jataí - UFG www.jatai.ufg.br/geografia \\ | Jataí-GO | N.10 | jan-jun/2008

compreende essencialmente por formas de fabricação de "capital não intensivo" (SANTOS, 1979). Resultando no aparecimento e na permanência de estabelecimentos comerciais modestos e de pequena dimensão, na inexistência de produtos modernos a varejo, na relação de compra e venda com base no vinculo de amizade e de confiança, a exemplo os mercadinhos que fazem uso das cadernetas. Sendo assim, o comércio encontrado na cidade de Gavião Peixoto é do tipo a varejo com pouca expressividade, mas que possui certa representatividade para a cidade como um todo, mesmo não havendo uma grande variedade nas marcas dos produtos.

\section{3 - A Periferia de Gavião Peixoto}

A cidade de Gavião Peixoto, apesar de ser de pequeno porte, apresenta vazios urbanos, resultando em uma descontinuidade do tecido urbano; os bairros localizados na porção leste da cidade não se encontram conectados com a porção central, existindo apenas algumas ruas que interligam ambos os setores, como mostra a figura 03 .

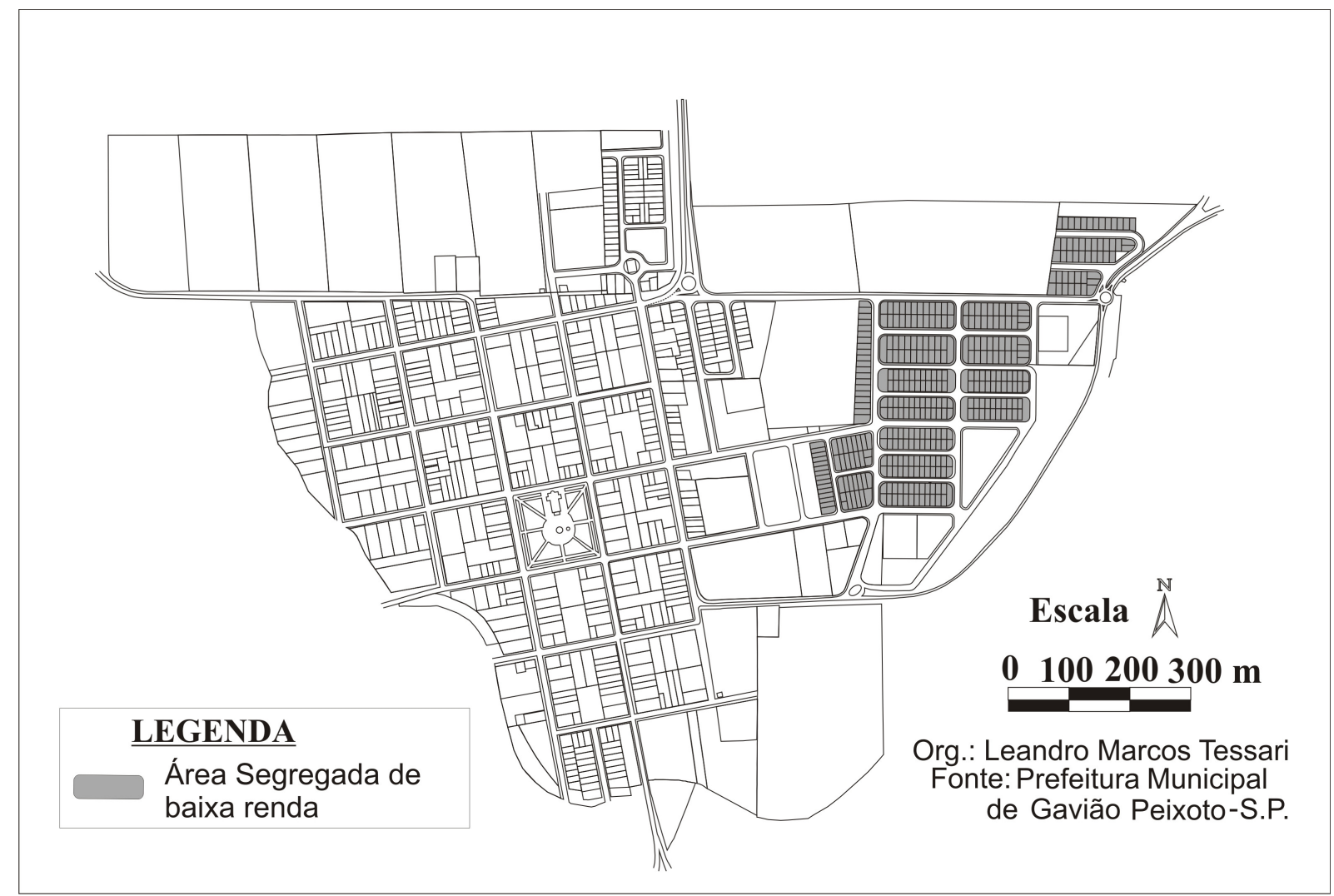

Figura 3: Planta Urbana de Gavião Peixoto - SP.

O sistema viário desta cidade se encontra estruturado como um tabuleiro de xadrez. Já com relação a espacialidade das quadras, percebe-se novamente uma disparidade entre o 


\section{GEOAMBIENTE ON-LINE \\ Revista Eletrônica do Curso de Geografia do Campus Jataí - UFG \\ www.jatai.ufg.br/geografia \\ | Jataí-GO | N.10 | jan-jun/2008

centro e as áreas recém urbanizadas, principalmente no que diz respeito ao solo urbano. $\mathrm{Na}$ sua grande maioria, as quadras da porção central possuem, aproximadamente, 14400 metros quadrados, com uma variação de dezesseis a vinte e sete lotes por quadra, sendo que, na grande maioria, cada lote possui uma metragem de 1200 metros quadrados. Já na porção leste, a metragem das quadras é de aproximadamente 11680 metros quadrados. A quantidade de lotes porta-se sempre de maneira constante, com vinte e seis a vinte e quatro lotes por quadra. Percebe-se uma padronização dos lotes, com 162 metros quadrados cada um. Assim, apenas em uma avaliação quantitativa relativa ao tamanho das quadras e de seus respectivos lotes, nota-se todo um panorama diferenciado entre o centro e a periferia da cidade de Gavião Peixoto.

Em um primeiro momento, tais fatos podem ser explicados devido ao fato de um dos bairros localizados na porção leste da cidade ser fruto de um empreendimento imobiliário promovido pelo Estado, ou seja, casas populares construídas pelo Governo Estadual no início da década de 1990, quando o município ainda era distrito de Araraquara.

Entretanto, observa-se um fato interessante, nas áreas recém urbanizadas localizadas nas porções leste e norte da cidade: os loteamentos realizados por particulares possuem as mesmas dimensões do empreendimento promovido pelo Estado. Assim sendo, são vários os agentes responsáveis pela formação e consolidação do processo de periferização no espaço urbano. Conclui-se que a expansão da cidade para as áreas periféricas é resultado de uma somatória de interesses, produzidos pelo poder legal constituído (o Estado) e, subjacente a ação estatal, as classes detentoras de capital (FURLANETO et. al., 1987). Por se tratar de uma cidade de pequeno porte, o número de equipamentos urbanos mostra-se também reduzido.

O espaço urbano de Gavião Peixoto vem passando por diversas transformações, principalmente pela incorporação de áreas que outrora possuía uso rural e atualmente estão sendo incorporadas à cidade, resultando no processo de periferização urbana. Os bairros recentemente loteados localizados na franja urbano-rural da cidade possuem pouca infraestrutura urbana, existindo apenas: água encanada, luz elétrica, e sistema de esgotamento sanitário.

Para melhor entendimento desses fatos, a figura 04, tem as imagens que contribuem para melhor esclarecer e reforçar a noção de segregação urbana visualizada na área de estudo. 


\section{GEOAMBIENTE ON-LINE \\ Revista Eletrônica do Curso de Geografia do Campus Jataí - UFG www.jatai.ufg.br/geografia | Jataí-GO | N.10 | jan-jun/2008

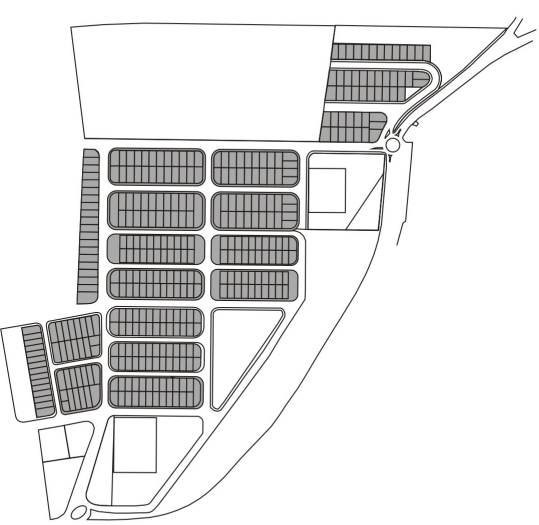

Escala

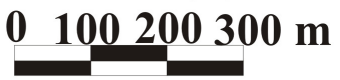

Org.: Leandro Marcos Tessari Fonte: Prefeitura Municipal de Gavião Peixoto-S.P.

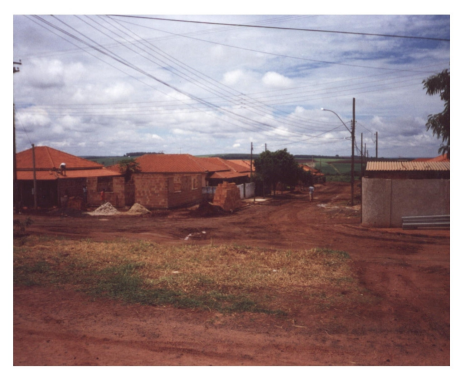

Casas, em construção, localizadas na zona leste

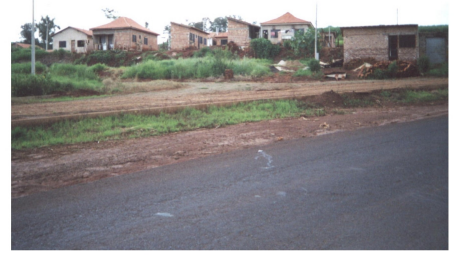

Carência de infra-estrutura urbana na zona leste da cidade
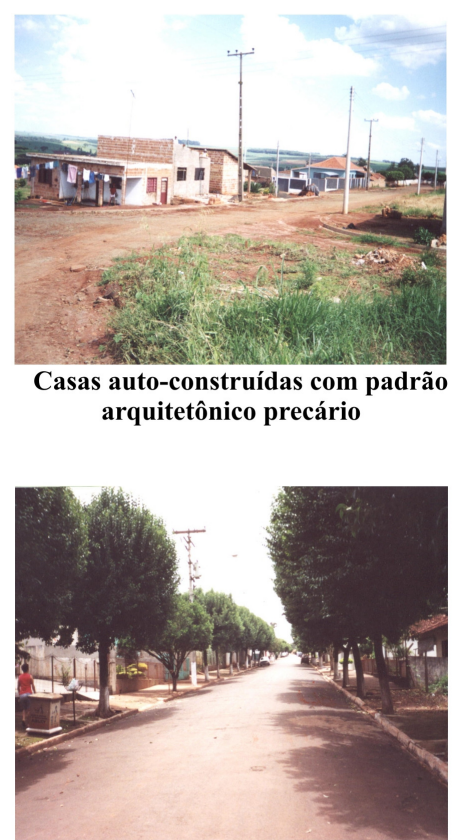

Rua central da cidade em estudo padrão diferente da área periférica

Figura 4: área de Estudo com Imagens do Local

\section{4 - Resultados}

A pesquisa de campo foi realizada através da aplicação de questionários, com questões qualitativas e quantitativas, em residências localizadas nos bairros periféricos de Gavião Peixoto. Posteriormente, foi calculada a amostra, obteve-se o número de setenta e quatro questionários que foram aplicados, com uma margem de erro de $10 \%$ e com um índice de confiança de 95\%. O interesse principal da elaboração e aplicação dos questionários foi identificar as condições socioeconômicas da população residente na porção periférica da cidade de Gavião Peixoto. Tem também o objetivo de mostrar as reais condições de perspectivas dessa população em relação ao desenvolvimento do município com a instalação do Pólo Aeroespacial e os possíveis reflexos desse empreendimento no processo de urbanização, em especial, da periferização.

A partir dos dados coletados em campo, chegou-se à conclusão que a maior parte dos chefes de família possuem apenas o ensino fundamental incompleto, representando $56,4 \%$ da população. O índice de analfabetismo é elevado, representando um total de 16,6\%, principalmente quando comparado ao índice do Estado de São Paulo, que é de 6,6\% e da 


\section{GEOAMBIENTE ON-LINE \\ Revista Eletrônica do Curso de Geografia do Campus Jataí - UFG \\ www.jatai.ufg.br/geografia \\ | Jataí-GO | N.10 | jan-jun/2008

Região Administrativa Central, que é de 7,8\%, segundo dados demográfico da Fundação SEADE no ano de 2000. No que toca os demais níveis de escolaridade analisados, percebe-se uma queda acentuada dos índices, haja vista que grande parte dos chefes de família encontram-se empregados em serviços que exigem pouco grau de instrução, principalmente ligados ao setor primário da economia, ou até mesmo autônomos. De acordo com os indivíduos entrevistados, nenhum deles declarou que os chefes das respectivas famílias cursaram ou estavam cursando o nível superior de ensino.

Grande parte dos chefes de família, 70,5\%, encontram-se empregados. Quando perguntado sobre o número de desempregados na residência, 56,1\% dos entrevistados declaram existir pelo menos uma pessoa desempregada na família. Tal fenômeno representa a situação que o país vem enfrentando, ou seja, uma acentuada queda no número de postos de trabalho, nos diversos setores da economia, especialmente no campo, devido a uma constante modernização da agricultura.

A renda familiar da população residente nos loteamentos localizados na porção periférica da cidade de Gavião Peixoto é baixa, sendo que 50\% do total de domicílios apresentam uma renda entre 01 a 03 salários mínimos referente a setembro de 2006 (R\$ 350,00). Os respectivos serviços exercidos pela população entrevistada encontram-se pautados na relação muito trabalho pouco rendimento. Os demais índices salariais da renda familiar se encontram na faixa de 03 a 05 salários mínimos e representam 32,7\% dos domicílios, os $12,8 \%$ restantes, representam a faixa salarial entre 5 a 10 salários mínimos devido a um maior número de pessoas que contribuem para a renda familiar.

$\mathrm{Na}$ maioria dos domicílios analisados a renda familiar é composta por 01 ou 02 indivíduos representando mais de três terços, ou seja, 78,2\% do total.

A quantidade de pessoas que residem na mesma casa representa, ainda, de maneira geral, uma realidade da família brasileira constituída na sua grande maioria por quatro ou cinco indivíduos. Tal fato também pode ser observado no caso da área periférica de Gavião Peixoto, pois $59 \%$ do total das residências são compostas por quatro ou cinco indivíduos. A quantidade de famílias que habitam as residências analisadas é, na sua grande maioria, composta por residências unifamiliares, representando um total de $85,9 \%$.

Quanto ao número de residências no mesmo lote, 75,6\% do total dos domicílios possuem apenas uma residência no mesmo lote. No entanto, lotes com duas residências são encontrados em $23,1 \%$ do total analisado. Convém salientar que vários casos, cujos 


\section{GEOAMBIENTE ON-LINE \\ Revista Eletrônica do Curso de Geografia do Campus Jataí - UFG \\ www.jatai.ufg.br/geografia \\ | Jataí-GO | N.10 | jan-jun/2008

moradores dos lotes com mais de uma residência, pertencem a mesma família, demonstrando que estas residências não são para fins especulativos.

Todas as habitações são de alvenaria. No entanto, nota-se uma heterogeneidade nos padrões dessas habitações, ou seja, 55\% são de padrão simples, 14\% de padrões médios e $31 \%$ são precários ${ }^{4}$. Quanto ao estado de conservação dos imóveis pode ser classificado, na sua maioria, entre regular e bom.

No que diz respeito a situação dos imóveis existentes na periferia de Gavião Peixoto, o dados coletados em campo revelaram que 71,8\% dos imóveis são próprios, construídos no sistema de auto-construção; há também 18\% desses imóveis financiados, do conjunto habitacional popular construído pelo governo do estado no início da década de 1990, cujos moradores ainda não são proprietário, mas sim mutuários; existe ainda imóveis cedidos e alugados, representando um total de 3,8\% e 6,4\% respectivamente. A respeito desses dados convém pontuar duas situações, o antes e o após a instalação do EMBRAER. A aquisição de terrenos na cidade, antes da instalação do Pólo Aeroespacial era facilitada, visto que o preço da terra urbana tinha preço extremamente baixo e com condições de pagamento flexíveis, acertadas entre os interessados. No mesmo prisma, os moradores que residem nos imóveis alugados alegam um aumento substancial nos preços praticados pelos proprietários dos imóveis e que a solução seria abandonar a cidade de Gavião Peixoto e residir no distrito de Nova Paulicéia, ou até mesmo em cidades vizinhas, onde os preços dos aluguéis não sejam supervalorizados.

A maior parte da população residente na porção periférica da cidade de Gavião Peixoto não é originária desta localidade, mas instalada há mais de dez anos, correspondendo a um total de 53,8\%. Grande parte dessa população é proveniente do Estado do Paraná; por outro lado, pouquíssimas são as pessoas oriundas dos Estados da porção nordeste do Brasil. A busca por emprego, principalmente no campo, foi o principal motivo de deslocamento dos paranaenses, devido à adoção do sistema agro-exportador implantado neste estado que não necessita de mão-de-obra abundante como, por exemplo, a soja; $23,1 \%$ do total da população entrevistada são da própria Região Administrativa Central do estado de São Paulo. O motivo

${ }^{4} \mathrm{O}$ entendimento dos padrões habitacionais neste trabalho corresponde: Precário: habitações improvisadas ou inacabadas; Simples: habitações populares construídas e/ou financiadas por órgãos governamentais, possuindo no máximo de $70 \mathrm{~m}^{2}$ de área construída - padrão COHAB (Conjunto Habitacional Popular) e CDHU (Companhia de Desenvolvimento Habitacional e Urbano do Estado de São Paulo); Médio: habitações de melhor padrão construtivo, maior dimensão e acabamento completo. 


\section{GEOAMBIENTE ON-LINE \\ Revista Eletrônica do Curso de Geografia do Campus Jataí - UFG \\ www.jatai.ufg.br/geografia \\ | Jataí-GO | N.10 | jan-jun/2008 |

alegado por esta população é o mesmo: a busca por trabalho. Por fim, 15,4\% do total da população entrevistada são de Gavião Peixoto e o restante, 7,7\% do total são oriundas de outras regiões do estado de São Paulo.

A falta de pavimentação asfáltica, o número restrito de equipamentos urbanos, infraestrutura e oportunidade de trabalho foram aspectos negativos apresentados pelos moradores dos bairros periféricos de Gavião Peixoto. Por outro lado, tranqüilidade, sossego, vida cotidiana simples, poucas diferenças econômicas, excelente qualidade de vida, laços de amizade foram respostas dadas pelos mesmos moradores como aspectos positivos. A partir desses aspectos, pode-se notar algo interessante, principalmente, no que diz respeito à relação bairro/cidade. Poucos bairros, com medidas modestas, e um espaço urbano pequeno, resultou em um não pertencimento ao espaço do bairro, pois grande parte da população entrevistada não reconhece o bairro como subdivisões espaciais do urbano, ou seja, a cidade é vista como um todo.

\section{5 - Conclusão}

O processo de segregação socioespacial, na periferia de Gavião Peixoto teve início com a construção do Conjunto Habitacional Popular pelo poder público, quando este ainda era distrito de Araraquara, havendo uma acentuação do fenômeno com a formação de vazios urbanos entre a área periférica e o centro. Esse fato tem revelado sérios problemas no que toca a estruturação urbanística da cidade, como o encarecimento da infra-estrutura urbana, a produção de descontinuidade no tecido urbano que favorece um acentuado e crescente processo de especulação imobiliária, longos deslocamentos entre os bairros periféricos e o centro, tendo em vista que a cidade não possui sistema de transporte coletivo. Dessa forma, nota-se entraves no desenvolvimento pleno da cidade, limitando ações de planejamento efetivas voltada à população local.

Esse processo é produto da intervenção do poder público como um dos agentes modeladores do espaço urbano. Dessa forma, nota-se como as políticas públicas que, em princípio, deveriam solucionar uma problemática inicial acabam por provocar um agravamento da situação, ou melhor, a partir da demanda habitacional provocou-se o surgimento da periferia resultando num processo de segregação sócio-espacial.

A situação observada na cidade de Gavião Peixoto, em especial na consolidação da área periférica, foi tão somente voltada a população não originária dessa localidade. A 


\section{GEOAMBIENTE ON-LINE \\ Revista Eletrônica do Curso de Geografia do Campus Jataí - UFG \\ www.jatai.ufg.br/geografia \\ | Jataí-GO | N.10 | jan-jun/2008

implantação do Conjunto Popular visou a solução de uma demanda populacional que, a priori, não foi gerada exclusivamente pela população local, mas a partir de uma mobilidade intraurbana de população.

A área de estudo é bastante homogênea no que diz respeito às construções, na grande maioria auto-construídas; arruamentos sem pavimentação asfáltica, porém, com sistema de esgotamento sanitário e energia elétrica; carência de equipamentos urbanos, não somente restrito a essa porção da cidade. Constituída basicamente por uma população de baixa renda e com elevado índice de analfabetismo, revela uma restrita expectativa de novas oportunidades de trabalho mesmo com a instalação do Pólo Aeroespacial.

\section{6 - Referências Bibliográficas}

ALMEIDA. E. P. de A metropolição - peirferização brasileira no período técnico - científico - informacional. 2000. 189f. Dissertação (Mestrado em Geografia) Faculdade de Filosofia, Letras e Ciências Humanas, Universidade de São Paulo, São Paulo, 2000.

BEZERRA, V. M. d'A. et. al. Periferização urbana no Brasil: um projeto de estudo nas áreas metropolitanas. Revista Brasileira de Geografia, Rio de Janeiro, v.45, n. 01, p. 51 - 92, 1983.

CARLOS. A. F.A. O sentido da cidade: as possibilidades da análise geográfica. In: SPÓSITO, M. E. B. Urbanização e Cidades: Perspectivas Geográficas. Presidente Prudente: UNESP Faculdade de Ciência e Tecnologia, 2001.p. 421 - 431.

Repensando a Geografia Urbana: Uma nova perspectiva se abre. In: CARLOS, A. F.A. Os caminhos da reflexão sobre o urbano e a cidade. São Paulo: Edusp, 1994. p. 157 199.

A (re) produção do espaço urbano. São Paulo: Edusp, 1994.

CORRÊA, R. L. Globalização e reestruturação da rede urbana: uma nota sobre pequenas cidades. Território, Rio de Janeiro, v.4, n.6, p. 43 - 53, jan./jun. 1999.

FUNDAÇÃO SISTEMA ESTADUAL DE ANÁLISE DE DADOS. São Paulo, nov. 2001. Seção Estatísticas Vitais. Disponível: <http://www.seade.gov.br>. Acesso em: 09 de jan. 2003.

FURLANETO, D. A.; CRUZ, J. M.; ALMEIDA, R. S. de. Promoção Imobiliária e Espaço residencial da Classe Média na Periferia Metropolitana do Rio de Janeiro. Revista Brasileira de Geografia, Rio de Janeiro, v.49, n. 02, p. 27 - 56, 1987.

GOTTDIENER, M. A produção social do espaço urbano. São Paulo: Edusp, 1993. 


\section{GEOAMBIENTE ON-LINE \\ Revista Eletrônica do Curso de Geografia do Campus Jataí - UFG \\ www.jatai.ufg.br/geografia \\ | Jataí-GO | N.10 | jan-jun/2008 \\ CEO \\ БMMBIENTE \\ ISSN 1679-9860}

\section{INSTITUTO BRASILEIRO DE GEOGRAFIA E ESTATÍSTICA. Cidades.}

<http://www.ibge.gov.br>. Acesso em: 09 de jan. 2003.

KOWARIK, L. Espoliação urbana, lutas sociais e cidadania: fatias de nossa história recente. Espaço \& Debates (revista de estudos urbanos), São Paulo, n. 40, p. 105 - 113, 1997.

LEFEVRE, H. A Revolução Urbana. Tradução de Sérgio Martins. Belo Horizonte: Ed. UFMG, 1999.

LOWEN, C. L. Favelas: um aspecto da expansão urbana de Ponta Grossa - P.R. 1990. 174f.

Dissertação (Mestrado em Organização do Espaço) - Instituto de Geociências e Ciências Exatas, Universidade Estadual Paulista, Rio Claro, 1990.

MARQUES, E. C.; BICHIR, R. M. Investimentos públicos, infra-estrutura urbana e produção da periferia em São Paulo. Espaço \& Debates (revista de estudos urbanos), São Paulo, n. 42, p.9 - 31, 2001.

MAUTNER, Y. A periferia como fronteira de expansão do capital. In: DEÁK, C.; SCHIFFER, S. R. (Org.). O processo de urbanização no Brasil. São Paulo: Edusp, 1999. p. $246-259$.

PEREIRA, G. A natureza (dos) nos fatos urbanos: produção do espaço e degradação ambiental. Desenvolvimento e Meio Ambiente, Curitiba, n. 03, p. 35-51, jan/ jun. 2001.

PREFEITURA MUNICIPAL DE GAVIÃO PEIXOTO. História e Localização. Gavião Peixoto: Prefeitura Municipal, 2001.

PROST, B. Du Rural au Peri-Urbain: Conflit de Territoire et Requalification de L'Espace. Revue de Géographie de Lyon. v. 66, n. 2, p. 96 - 102, 1991.

RIBEIRO, L. C. de Q.; LAGO, L. C. Reestruturação nas Grandes Cidades Brasileiras: o modelo centro/periferia em questão. Artigo obtido no site: http://www.observatoriodasmetropoles.ufrj.br/download/reestruturacao_cidades.pdf IPPUR UFRJ, Rio de Janeiro, p. 01 - 19, 1994.

SANTOS, M. A Urbanização Brasileira. 5. ed. São Paulo: Edusp, 2005. 176p.

Tendências da Urbanização Brasileira no fim do século XX. In: CARLOS, A. F.A. Os caminhos da reflexão sobre o urbano e a cidade. São Paulo: Edusp, 1994. p. 17 - 26.

$O$ espaço dividido: os dois circuitos da economia urbana dos países subdesenvolvidos. Rio de Janeiro: Francisco Alves, 1979. 345p.

; SILVEIRA, M. L. O Brasil: território e sociedade no início do século XXI. Rio de janeiro: Record, 2002. 


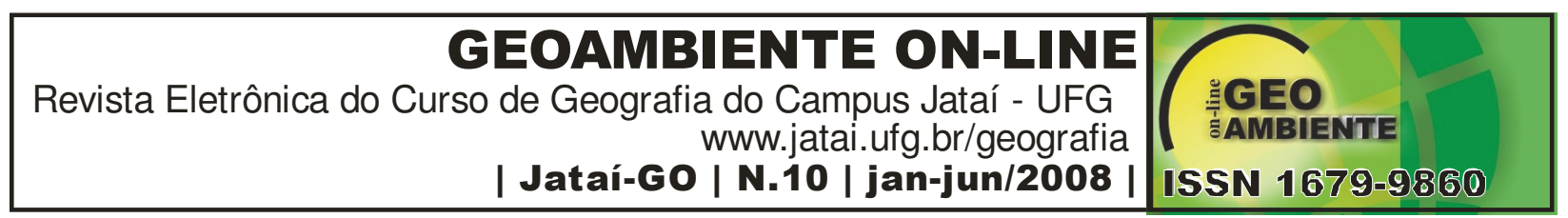

SINGER, P. O uso do solo urbano na Economia Capitalista. In: MARICATO, E. (Org.). A produção capitalista da casa (e da cidade) no Brasil industrial. 2.ed. São Paulo: AlfaOmega, 1982.

SPÓSITO, M. E. B. A urbanização da sociedade: reflexões para um debate sobre novas formas espaciais. In: CARLOS, A. F. A. et. al. (Org.). O Espaço no Fim do Século: a nova raridade. 2.ed. São Paulo: Contexto, 2001. p. 83 a 99.

VILLAÇA, F. O espaço intra-urbano no Brasil. 2.ed. São Paulo: Studio Nobel, 2001. 